\title{
Determinants of Facebook Usage in Organizations and its Impact on Job Performance
}

\author{
Ramsha Zakariya* \\ Capital University of Science and Technology, Islamabad
}

\begin{abstract}
Facebook is the most trendy social network to date whose popularity is rising swiftly nowadays in our society. The overall purpose of this research is to evaluate the determinants of Facebook Usage at the work place and its impact on the job performance of the employees. A sample of 250 employees was drawn from Call Centers in Rawalpindi and Islamabad with the purposive sampling technique. Data were analyzed through Pearson correlation, regression analysis and A. F. Hayes macros to measure the results. The findings suggest that Socializing through Facebook is positively associated with job performance while information sharing and self status seeking are not directly associated with job performance. Moreover, a positive association exists between Facebook usage and employees job performance which is shown to mediate the relationship between socializing, information sharing and self status seeking through Facebook and job performance of the employees.
\end{abstract}

\section{Introduction}

The emergence of online social networking is a prompt outcome of the revolution of communication. An online social network site (SNS) is identified as web based service that allows individuals to (a) construct a public or semipublic profile within a bounded system, (b) articulate a list of other users with whom they share a connection, and (c) view and traverse their list of connections and those made by others within the system (Boyd, 2007). Social networks have large range such as Facebook, Twitter, Flickr, etc. that serve the users for different purposes, i.e. sharing content, messages, following topics trends discussed by people across the network, entertainment, etc (Chung et al., 2014). Out of all social networking sites, Facebook is the most popular social network in the world which was designed for building online presence of people. Previous studies suggest that users are attracted to using Facebook, but there are limited studies that address what actually determines the usage of Facebook among different users. The usage of social networks builds up the feelings of social status and self worth among users and hence it affects their behavior (Wilcox and Stephen, 2013).

Significant doubts remain over the business value of public social networks, especially non-businessoriented networks like Facebook. This study attempts to resolve the controversy of whether or not the use of Facebook by employees leads to added value for organizations by examining the determinants of Facebook usage and its effect on job performance. How-

*Corresponding author.

Email: ramshazakariya@yahoo.com ever, the situation is changing, as the number of business applications available on these sites increases. Social networks may also add significant value to such applications as problem solving, collaboration, knowledge management, information sharing, and collective intelligence (Turban et al., 2011). The social relationships built through social networks also have impact on business relationships (Zhou et al., 2007). Facebook can serve the employees for different purposes, such as it facilitates knowledge sharing through organizations, which is an important part of management practice (Reinholt et al., 2011) through which people can share information with their colleagues, co workers and friends. Such information can be the exchange of work related information, strategic information and industry trends. Sharing of information among workers through social networks facilitates organizational learning; this source is effective from employees stand point as it boosts up the motivation level and creates organizational learning in low budget. (Ribeiro Soriano et al., 2012). The information rich networks improve work performance of employees and quantify its effects on productivity of employees (Wu, 2013).

Motivation theory (Deci \& Ryan 1975) explains why users are motivated to use the Facebook as this theory focuses on behavioral aspect of accepting information technology and users can have intrinsic motivation (entertainment, socialization) or extrinsic motivation (for acquiring information and seeking self status). Both the factors affect the motivation to use Facebook.

Even though social networkings usage has fasci- 
nated the media considerably for the previous few years, now it has become a subject matter of academic investigation. (Wills and Reeves, 2009); it is the fastest emerging tool in networking that has been attracting the industry as well as academia and continues to grow at a fast pace (Lin and Lu, 2011). Many of the researches on social networking sites from the college student data are not appropriate for the business world. Moreover, Kotlarsky and Oshri (2005) indicate that the prime focus of literature on information systems distributed on global terms has been on technical aspects for the projects of system development and mostly inappropriately addressed behavioral features. In addition, different studies have addressed the usage of Facebook according to demographics, such as use of Facebook by college and university students (Steinfield et al., 2008) and its usage and effect of age, gender and type of personality in emerging adults (Correa et al., 2010), there are limited studies that have addressed the usage of Facebook by the employed population. This study seeks to study the usage of Facebook by the employees.

Social networking sites are used for different reasons by different types of users. A persons gender, parental educational background, race and ethnicity are all linked with use of social networking sites (Hargittai, 2008). Based on suggestions of the aforementioned study, the current study examines the usage of social networking sites by telecom sector organizations of Pakistan targeting a specific sector having a different background and culture. This study will be conducted in the context of telecom firms as these firms are identified to provide internet access to their employees to accomplish job roles. In this regard, work styles adopted by telecom sector organizations can be identified as group based where employees have a high degree of flexibility in their work and have a high degree of interaction with their work colleagues. The objective of this study is to test the model in Telecom Sector of Pakistan and its implications for this sector and its results can be applicable on other sectors too. This study will survey participants, who are either full- or part time employees, about the Facebook use, its determinants, and job performance.

Pakistan is experiencing an increase in the usage of online social networking (Google Insight). Pakistani users of the social networking site Facebook crossed 10 million, according to Facebook Ads Manager (Source: The express Tribune) and it is expected to be growing at an accelerating phase over the years 2014 and 2015. However, according to Google Insight, Pakistan has an internet penetration rate of 11 percent. In the current scenario, if we check the theory and literature, we have very little research about the usage of Facebook in business context in Pakistan so this study can fill the gap for research in the rapidly emerging social media and its implications for organizations.
Studying the effect of social networking site use in the workplace on job performance is important for several reasons. First, professionals in charge of human resource departments will benefit from understanding the associations elicited by this study. Understanding relationships between Facebook use in the workplace and job performance can help reveal the underlying rationale for organizations to either allow or disallow the use of Facebook in the workplace. Organizations are searching for available means to increase employees job performance. If the use of Facebook turns out to be one of these means, organizations will be able to add the use of Facebook in the workplace to their arsenal of practices to enhance job performance. The findings of this study will reveal whether the belief that happy workers work harder holds in the context of social networking site use in the workplace.

It is expected that the findings of this study will provide insight into job related benefits and issues associated with Facebook to allow individuals, organizational leaders, and employees to better understand and utilize online social structures for success. Further, it is expected that the findings of this study will be a source of general guidance in stimulating future research in this area.

\section{Literature Review}

\subsection{Facebook Usage as a Type of Cyberloaf- ing}

Internet usage at the workplace has revolutionized the way work is done to improve work performance in a number of ways. Most of the employees in organizations have access to internet; some of them use it for job accomplishing purposes, others might use it excessively for personal purposes such as personal emailing, social networking such as Facebook, Twitter, etc. and browsing through other non-work related websites. Lim (2002) termed the activity of the usage of organizations internet resources by the employees for personal purposes during working hours as Cyberloafing.

Different organizations may consider cyberloafing behaviors of employees differently i.e. acceptable or unacceptable in that organization as per their severity. Many organizations render cyberloafing as an insidious issue (Ugrin et al., 2012). Serious cyberloafing such as online gambling and excessive usage of non work related sites for personal usage consume more time of the employee and hence reduce their productivity and is considered as undesirable behavior at work, while minor cyberloafing acts such as social networking, sending or receiving personal email can be considered as harmless (Blanchard \& Henle, 2007), hence it depends upon the type of cyberloafing activity and the organi- 
zation to take it as tolerable or not.

The propensity of employees to use organizational internet resources for non work purposes has been increasing with their increased access to internet at workplace. A very common way to Cyberloaf is considered as usage of social networking sites at workplace, which are widely used by millions of people across the world, and becoming a noteworthy part of peoples lives (Cotten 2008). The most popular social networking site capturing the highest proportion of internet usage traffic is the Facebook which was created in 2004 by Mark Zukerberg, being perceived as a trustworthy SNS by users (Fogel and Nehmad, 2009). Facebook was created for the purpose of socialization among people; it enables interaction and bonding, sharing of information among friends, colleagues and co-workers, or other people who are around. It is the most popular social networking site in Asia, reporting to have approximately 212 million users in Asia (Jenny et al., 2013)

Literature suggests both negative and positive consequences of cyberloafing through social networking such as Facebook with some arguing that it may harm the organizations while others suggesting that it may increase employee performance. It may be considered as wastage of time at work (Malachowski, 2005) and as a workplace deviant behavior caused by counterproductive behavior, which distracts the workers to accomplish their main job roles (Lim, 2002), resulting in decreased productivity and performance of employees (Liberman et al., 2011). However its positive effects have also been discussed by some authors. Bakker et al. (2004) propose that when employees are exposed to higher job demands, and longer working hours in the push for higher productivity by the employers (Ferreira and Du Plessis, 2009), the employees get emotionally exhausted. Usage of Facebook can be a solution as Lim and Chen (2009) describe that social networking at workplace can reduce stress and relax the employees, breaking their exhaustion. Usage of Facebook can be considered as a recovery for the employee to recharge and energize them to get ready for getting back to work. Furthermore, Lim and Teo (2005) posit that the internet usage has merged the boundaries of workplace and home, allowing employees to transfer additional work to home than the personal tasks to the place of work, so usage of companys internet for social networking can be justifiable, and may be taken as allowing workers some time for making personal calls through companys telecom resources.

The previous researches that consider Facebook usage harmful for the organizations are overemphasizing its negative consequences; this research further argues that using internet at workplace for personal usage could be considered in resource based point of view that emphasizes the motivation, satisfaction, empowerment, development and work life balance of the employees, which captures sustainable competitive ad- vantage through a skilled and knowledgeable workforce. These skills and knowledge can be learned through usage of Facebook which is considered as minor cyberloafing and is evident in providing a balance between work and family, cutting down stress, developing new ideas and skills through new acquired knowledge and networking (Blanchard \& Henle, 2007).

In this era, organizations cant prohibit usage of social networks as all business functions seem to be shaped to some degree by online social networks such as marketing and advertising, recruiting and selecting activities etc (Smith \& Kidder, 2010); employees are exposed to these resources to accomplish different tasks such as emailing and researching for information online. Some of them often use IT mechanisms e.g. firewalls and blocking software, employees may still have access to internet and social networking sites (Facebook) through their personal communication devices like laptops, tablets or smart phones. Hence organizations need to decide whether to allow or control and prevent usage of Facebook, as the minor form of cyberloafing (Lim \& Teo, 2005), by understanding the determinants and outcomes of using it at workplace. This study further explores the factors that determine Facebook usage by employees at workplace and their effects on the job performance of employees.

\subsection{Why People Use Facebook at Work- place}

As the usage of Facebook has been showing an increasing trend, and is expected to increase, literature suggests different factors that contribute to the usage of Facebook. It is important to identify those factors. The literature shows Facebook facilitates constructing individual relations, enhancing personal linkages, to find people who have alike experiences, arguing common areas of interest, and linking to the friends, far family members and work colleagues (Ferreira and Du Plessis, 2009). Furthermore, the usage of social networks builds up the feelings of social status and self worth among users and consequently affects their behavior (Wilcox and Stephen, 2013). This research sums up the most common factors that influence Facebook Usage in the workplace by employees as Information Sharing, Socialization and Self Status Seeking.

\subsection{Socializing Through Facebook}

Everyday hundreds and millions of people all over the world use Facebook for accessing online social networks for communicating and sharing their experiences with others. It has become an essential instrument for connecting people \& sharing information. Facebook helps people in making a profile of themselves in which they can add their personal information and also can upload pictures and videos, thus 
these sites help people in sharing their personal information with others (Wilcox and Stephen, 2013), which gives its users an opportunity to share, express, and connect with others. Users can share their interests, their norms, friends, information regarding workplace, etc. (Hugl, 2011), which may have an influence on the business relationships that are informal in nature. Consequently, they prioritize the border notion of social network in order to incorporate personal relationships with government officials \& business professionals, also with relatives and with friends (Zhou et al., 2007).

\subsection{Self Status Seeking Through Facebook}

Literature suggests that although there is hot debate on usage of Facebook, still there is less evidence on how individuals use it for the sake of self representation, conveying status and information (Scott, 2014). There are a very few researches on the self expression, presentation and status seeking through Facebook because research on Facebook is only at the surface level, though Facebook acts as a source for individuals to seek self status, self expression, affinity and self monitoring which can have crucial effects on a persons private and professional life (Rosenberg and Egbert, 2011).

It has been stated that informational giving is a phenomenon dominated by status and status seeking, and also that status gushes are more likely to sustain simulated communities than real ones (Lampel and Bhalla, 2007). Status seeking is thereby viewed as a social urge that motivates participants to invest their time and effort in gifting their experience to others regardless of the thought of direct benefit to themselves in return; and is also trustworthy source of enduring participation, ensuring the survival and growth of virtual communities. Alhabash et al. (2014) found out that out of all the reasons of usage Facebook, Self status seeking is one of the most important and strong factor in determining Facebook Usage Intensity.

\subsection{Information Sharing Through Face- book}

With the passage of time, firms have shifted towards the use of web 2.0 as a knowledge sharing tool through which they can perform much better as compared to the performance level measured by using conventional methods. By transcending the approach that knowledge is something to be owned, bought and sold, YouTube, Facebook, Google and many other such sites have ushered in a new age of sharing which has been easily and quickly accepted and embraced by millions. Sharing of information through Facebook such as recipes, travel guides, and weather forecasts, business guides, work related information gathering etc has be- come a common practice (Belk, 2010). Facebook, providing its users with a number of contacts and having an appeal to the advantages of the variety of information, learning and tactic knowledge, benefits the users in acquiring that information and knowledge on time through their social contacts (Zhou et al., 2007).

\subsection{How Facebook Usage Affects Job Per- formance}

Organizations have been devoting much attention to how the minor cyberloafing such as using Facebook affects the performance of employees. Theories of performance suggest that performance is a function of ability and motivation and hence it is related to social support. The literature shows that online social networks such as Facebook facilitate constructing individual relations, enhancing personal linkages, to find people who have alike experiences, arguing common areas of interest, and linking to the friends, far family members and work colleagues (Ferreira and Du Plessis, 2009); hence affecting the individual characteristics, motivational factors and emotional states, impacting the job performance (Siu et al., 2013).

Empirical studies suggest that Facebook enhances the skills and abilities of employees that may lead to enhanced performance. The outcomes of a study pointed out that young people who had been using Facebook for more than a year gained greater scores in tests of verbal ability, working memory, and spelling as compared to their peers who had been using it for a shorter time period (Alloway et al., 2013); and these skills can help employees accomplish their tasks in better way. Literature finds that Facebook users have greater tendency to take risk as compared to non users of Facebook (Fogel and Nehmad, 2009), this ability may enhance workers capabilities to perform to changing situations in the organization.

Moreover, Zou and Ingram (2013) did their research by breaking down Job performance into decision-making, creativity, teamwork, and task execution. They found that all those social networks which cross the firms boundaries had actually a positive link with decision-making \& creativity, whereas networks within the firm deem to have a positive link with teamwork, \& task execution, which consequently improves performance at work. A latest research by Moqbel et al. (2013) is recognized to be the beginning work on the influence of social media use in a firm on the outcomes that are related to job, inclusive of job performance, job satisfaction, \& organizational commitment. Predominantly, their conclusions gave assistance \& support concerning the positive influence of social media use in firms. Valle et al. (2012) suggest that organizations must use some motivation strategies to retain employees in the organization; usage of social media like Face- 
book can be helpful in creating employee satisfaction, which is positively related to job performance (Somers and Casal, 2009).

According to the evidence provided by Coker (2013) from data collected through survey, concluded that browsing internet for something other than work may have positive influence, for the workers, at least, in terms of reinstituting concentration of the workers as a result from a nationwide survey found worker perceived productivity benefits. These conclusions recommend that internet browsing other than work related purpose i.e. cyberloafing should not always be considered as negative workplace behavior but may be viewed as another informal break activity, in the same manner stepping outside for a cigarette is accepted or may be a trip to the water cooler.

The literature reviewed proposes the following hypotheses:

H1. Facebook usage mediates the relationship between socializing and job performance.

H2. Facebook usage mediates the relationship between self status seeking and job performance.

H3. Facebook usage mediates the relationship between information sharing and job performance.

\subsection{Outcomes on Job Performance}

Organizations and researchers have a concern with the Job Performance of employees. For the enhancement of job performance, researches have been conducting studies for decades. According to Porter and Lawler (1968) performance is influenced by attitudes. Empirical evidence of Lawler and Porter (1967) showed that satisfaction that is of higher order needs, is closely related to performance. This research focuses on individual needs such as entertainment, socialization and information sharing satisfied through Facebook and its impact on job performance.

\subsection{Socialization through Facebook and Job Performance}

Socialization through social networks such as Facebook creates a sense of humility among individuals, which includes the ability to seek open advice and appreciating other people and sharing their personalities which is a predictor of success and high job performance of employees (Johnson et al., 2011). Prevailing sort of teamwork prioritize social support through informal social networks of employees (Carson et al., 2007), that may be built through Facebook, which depends and counts on employees networks and support that assist them to develop and grow connections with each other and consequently assists them in socialization within \& across teams that successively ends up in a positive team \& organizational outcomes. Such as, a capable individual in a team can be fundamental to maximizing social capital resources of the group, through high quality access to formal leaders in some other groups, via informal socializing ties, which were made through social networking (Oh et al., 2004).

Mathieu et al. (2008) argue that the interaction among individuals working together in teams is necessary to meet the individual, team level and organizational performance and suggest future researchers to study the interaction of group members through virtual social networks like Facebook. This study seeks to extend literature in this regard.

H4. Socialization through Facebook is positively related to Job Performance.

\subsection{Self Status Seeking Through Facebook And Job Performance}

Essentially based on the term status refers to a subjects comparative standing in a group, which in turn will be essentially based on esteem, integrity, or deference and hence, will be judged by the degree of success of these activities resulting in increasing esteem, integrity, or deference. Status seeking on Facebook or another social network may encompass external or internal goals that are; the subjects might seek status for virtuously economic and social advantage, but might also seek it for internal reasons like psychological and emotional ones. Granting, the two drivers are not mutually exclusive, their dominance will be determined via the nature of the group and social ties involved (Lampel and Bhalla, 2007). Judge and Bono (2001) in the light of theory of core self evaluations found out that self status and self esteem being the indicators of core self evaluations construct predict job satisfaction and performance significantly. Literature suggests that job performance is a function of individuals self concern and self orientation; therefore, self status builds up the relationship of job characteristics and job performance (De Dreu and Nauta, 2009).

Facebook acts as a means to increase self-status, which is related to both higher and increased beginner level of success and steeper job performance trajectories (Judge and Hurst, 2008). Any person with high social rank on a social network presumes to be treated pleasantly by others with whom she or he occupies oneself in economic \& social interactions. Any persons professional status may be associated with her or his level of job or the amount of promotions that he or she has earned in his or her professional career. Highstatus professionals that have proven track records of their performance may have a sensation that they have 
already built their capabilities (Sumanth and Cable, 2011). In this conception, an actor is successful because he can draw on the resources controlled by her alters, including information, money, power, and material aid (Borgatti and Foster, 2003) that may enhance individual performance.

H5. Self Status Seeking through Facebook is positively related to Job Performance.

\subsection{Information Sharing and Job Perfor- mance}

Sharing of information which takes place between individuals is a practice of great relevance which grows connections that will in a result help in giving a positive team \& organizational outcomes. Facebook usage helps in distributing different ideas which facilitate and amplify interaction among workers and extended engagement. Generally we can say that information services such as Facebook can be used for extrinsic effective and efficient utility working (Pihlström17 and Brush18, 2008) as sharing information through them leads to generation of innovative ideas which leads to better utilization or organizational resources (Tseng and Huang, 2011).

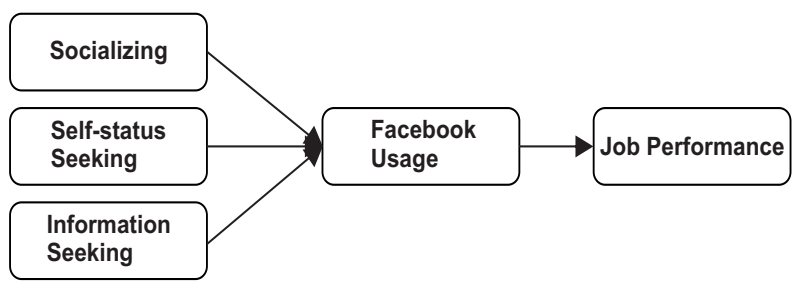

Figure 1: Theoretical framework.

Individual performance in knowledge-intensive work is linked with characteristics of both social connections and networks. Those relationships that cross the firms perimeters, physical obstacles, for example social networks like Facebook, yield distinct \& special information \& multiple outlooks to persons completing tasks at work (Cross and Cummings, 2004), because recognition and realization of expertise of others can influence performance by enhancing the likelihood of gaining required and appropriate information in order to resolve novel problems.

Sparrowe et al. (2011) studied the effects of both individual and group level social network ties and found that those individuals who are central players in advice gaining and seeking through social networks e.g. Facebook attained higher ratings of performance as opposed to those who hinder flow of information through networks.
H6. Information Sharing through Facebook is positively related to Job Performance.

\section{Methodology}

\subsection{Research Instrument}

In the instrument all the items were measured on a five-point Likert scale ranging from $1=$ strongly disagree, 2 = disagree, $3=$ Neutral, $4=$ Agree, $5=$ strongly. The scale for Facebook usage comprised of six indicators measuring the use of online social networking developed by Ellison et al. (2007). Value of Cronbachs Alpha was .704, which means that questions for usage of Facebook Usage are reliable. A five item scale developed based on Podsakoff and MacKenzie's (1989) was used to enumerate the job performance of the employees. Value of Cronbachs Alpha was .843, inidcating that questions of employee job Performance are reliable. The scale adopted for determinants of Facebook usage had 14 items and the Chronbach alpha was .804 .

\subsection{Population and Sample}

Employees of Telecom Sector from Rawalpindi and Islamabad have been targeted in this study. The sample was selected from Call Centers as their employees are well aware of Information Communication Technology, and their job demands access to the internet that may give them access to Facebook at workplace as well, therefore, they can efficiently demonstrate the whole population. Moreover, a majority of call center employees constitute the age group 18-25, the Facebook stats show the majority users also comprise this age group, so choosing a sample from this population for checking the determinants and outcomes of Facebook usage at workplace can be effective. Those call centers where the Facebook has been banned for employees; they were not included in the population.

The sample had been selected through Purposive sampling technique which is a form of non probability sampling, as the data had to be collected from the users of Facebook only, i.e., those employees who dont use Facebook were not included in the research sample.

250 questionnaires had been distributed to 10 different call centers in Rawalpindi and Islamabad out of which 210 had been returned. 9 questionnaires were discarded due to inappropriate response and 201 were used for the study.

\subsection{Sample Characteristics}

The sample consisted of 150 male respondents constituting $74.6 \%$ of the sample while female respondents were 51 , representing $25.4 \%$ of the population. The ratio of females in sample was low because of cultural 
Table 1: Means, Standard Deviations and Correlations

\begin{tabular}{|c|c|c|c|c|c|c|c|c|c|c|c|c|c|}
\hline & Variable & Mean & SD & 1 & 2 & 3 & 4 & 5 & 6 & 7 & 8 & 9 & 10 \\
\hline 1 & Gender & 1.25 & 0.436 & & & & & & & & & & \\
\hline 2 & Marital Status & 1.14 & 0.347 & $.162^{*}$ & & & & & & & & & \\
\hline 3 & Age & 1.5 & 0.53 & 0.008 & $.378^{* *}$ & & & & & & & & \\
\hline 4 & Qualification & 1.93 & 0.644 & 0.117 & $.290 * *$ & $.322^{* *}$ & & & & & & & \\
\hline 5 & Experience & 1.72 & 0.687 & -0.013 & $.310^{* *}$ & $.441^{* *}$ & $.216^{* *}$ & & & & & & \\
\hline 6 & Type Of Position & 1.92 & 1.074 & 0.001 & $.285^{* *}$ & $.413^{* *}$ & $.339 * *$ & $.444^{* *}$ & & & & & \\
\hline 7 & Socializing & 3.6318 & 0.8976 & 0.007 & -0.062 & -0.002 & $.198^{* *}$ & -0.02 & 0.043 & & & & \\
\hline 8 & Self Status Seeking & 3.4312 & 0.9631 & 0.091 & -0.011 & 0.04 & $.212^{* *}$ & 0.029 & 0.088 & $.622^{* *}$ & & & \\
\hline 9 & Information Sharing & 3.3466 & 0.8999 & 0.102 & 0.021 & 0.091 & $.160^{*}$ & $.141^{*}$ & 0.058 & $.405^{* *}$ & $.502^{* *}$ & & \\
\hline 10 & Facebook Usage & 3.568 & 0.976 & 0.034 & 0.009 & 0.106 & 0.091 & 0.091 & 0.041 & $.670^{* *}$ & $.678^{* *}$ & $.408^{* *}$ & \\
\hline & Job Performance & 3.8587 & 0.7916 & 0.055 & -0.092 & -0.018 & -0.01 & -0.005 & -0.007 & $.395^{* *}$ & $.354^{* *}$ & $.207^{* *}$ & $.493^{* *}$ \\
\hline
\end{tabular}

norms of Pakistan where females working in Night Shift are not encouraged and most of the outbound call centers have their operations in Night Shift (working on international projects). $86.1 \%$ respondents were single and $13.9 \%$ were married.

Table 2: Regression for Outcomes

\begin{tabular}{lccc}
\hline \multicolumn{1}{c}{ Predictors } & \multicolumn{3}{c}{ Job Performance } \\
& $\beta$ & $R^{2}$ & $\Delta R^{2}$ \\
\hline Step 1 & & & \\
Control variables & & 0.15 & \\
Step 2 & & & \\
Socializing & $.232^{* *}$ & & \\
Self Status Seeking & 0.109 & & \\
Information Sharing & -0.025 & 0.206 & $.191^{* * *}$ \\
\hline
\end{tabular}

Control Variables: Type of Position, Gender, Marital Status, Qualification, Experience, Age

$N=201,{ }^{* * *} p<0.01,{ }^{* *} p<0.05,{ }^{*} p<0.10$

The majority belonged to age group 18-25 representing $51.2 \%$ of the sample and other age groups $25-$ 34 and $35-44$ constituted 47.3 and $1.5 \%$ respectively of the sample. $59.7 \%$ had bachelor degree, $55.7 \%$ had an experience of 1-4 years and the junior staff from sales representatives constituted 43.8 percent of sample fol- lowing by senior staff which constituted $34.8 \%$.

\section{Results}

Table 1 represents the correlation analysis between the variables. The control variables show negative association with job performance while independent variables (socializing, self status seeking and information sharing) and the mediator (Facebook usage) are significantly and positively correlated with job performance, which support the study hypotheses. Socializing, self status seeking and information sharing are also positively correlated with Facebook usage.

Table 2 indicates the regression results of independent variables and their effect on job performance. A linear regression analysis was conducted to evaluate how well socializing, self status seeking and information sharing predict job performance. The control variables were controlled in the first step and independent variables were added in the second step to check the relationships. Socializing was significantly and positively related to job performance $(\beta=.232, \mathrm{p}<0.05)$ which supports $\mathrm{H} 4$ of the study i.e. socializing through Facebook is positively associated to job performance. Self status seeking $(\beta=.109, \mathrm{p}>0.05)$ and information seeking $(\beta=-.025, \mathrm{p}>.718)$ were not found to have significant relationship with job performance so H5; self status seeking through Facebook is positively associated to job performance and $\mathrm{H} 6$ were rejected. 


\subsection{Mediated Regression Analysis through A. F. Hayes}

For mediation analysis, indirect macro developed by A. F. Hayes was used to determine whether the change in the effect of the independent variable, after excluding the mediator in the model, is a significant change or insignificant and therefore whether the mediation effect is statistically significant. This method was to find out whether Facebook usage mediates the relationships between independent variables (socializing, self status seeking and information sharing) and job performance or not. The mediation was run for all the independent variables separately. Results were taken on $95 \%$ confidence interval and the number of bootstrap re-samples was 1000 .

The control variables were controlled and the analysis was done for H1, checking whether Facebook usage mediates the relationship between socializing and job performance. Results showed that all the paths between socializing to Facebook usage $(\beta=.75)$, Facebook usage to job performance (.40) and socializing on job performance (.36) were significant at $\mathrm{p}<0.01$ and $\mathrm{t}>2$. After controlling the mediator (Facebook Usage), the relationship between socializing and job performance has become insignificant at $\mathrm{p}=.17(\mathrm{p}>0.05)$ and $\mathrm{t}$ value decreased to $1.37(\mathrm{t}<2)$ suggesting that the mediating effect of Facebook on the relationship between socializing and job performance exists which validates Hypothesis 1.

For H2, after controlling the control variables, all the paths between self status seeking to Facebook usage $(\beta=.70)$, Facebook usage to job performance $(\beta=$ .40) and self status seeking to job performance $(\beta=$ .29) were significant at $p<0.01$ and $t>2$. After controlling mediator effects, the relationship between self status seeking and job performance became insignificant representing a $p$ value of $.71(p>0.05)$ and $t$ value decreased to $.36(t<2)$ indicating that Facebook usage acts as a mediator between self status seeking and job performance, and hence $\mathrm{H} 2$ is accepted.

For H3, after controlling effect of control variables, all the paths between information sharing to Facebook usage $(\beta=.43)$, Facebook usage to job performance $(\beta$ $=.40)$ and self status seeking to job performance (.29) were significant at $\mathrm{p}<0.01$ and $\mathrm{t}>2$. After controlling mediator effects, the relationship between information sharing and job performance became insignificant representing a $\mathrm{p}$ value of $.88(\mathrm{p}>0.05)$ and $\mathrm{t}$ value as .13 $(t<2)$ indicating that Facebook usage acts as a mediator between self status seeking and job performance, and hence $\mathrm{H} 2$ is accepted.

Results indicate that $\mathrm{H} 1, \mathrm{H} 2, \mathrm{H} 3$ and $\mathrm{H} 4$ are accepted while $\mathrm{H} 5$ and $\mathrm{H} 6$ have been rejected.

\section{Discussion}

The goal of this study was testing a research model explaining the expected connection between determinants of Facebook usage and their consequent effect on job performance of the employees. From a theoretical point of view, this study contributes to the Facebook Usage at workplace and job performance literature. This is the first study that addresses the reasons that why employees use Facebook at workplace and how does it affect their job performance.

In general, a good support was found for most of the studys hypotheses. The hypothesis that examined the relationship between socializing and job performance was accepted, in line with the previous studies (Carson et al., 2007; Johnson et al., 2011; Mathieu et al., 2008) suggesting that socializing through Facebook is associated to job performance and it can lead to enhanced employee performance. Pakistan is considered to be having collectivist culture (Hofstede, 1980) where people like to build ties and connections with others, which gives them a feeling of contentment. Facebook can serve employees with a way to socialize with friends, family members, and fellow coworkers and to keep up-to-date with what is going on in their social networks. This sense of social interaction has the potential to positively influence employees productivity with their jobs. This is because online Facebook usage in the workplace provides employees with a sense of social interaction. This social interaction serves as a social resource for employees in the organization which, in turn, enhances employees affective attachment to their organizations. In other words, engaging in social networking through Facebook may increase an employees access to support and resources, resulting in feelings of wanting to stay with the organization and working with full potential to attain organizational goals by performing the job roles better.

The mediation of Facebook usage between socializing through Facebook and job performance has been proved through results supporting literature e.g. Wilcox and Stephen (2013). Employees fulfill their need for socialization with others by using Facebook, the more socialization with others through Facebook they need, the more intense will be their Facebook usage, which makes them build relationships and ties and keeps them connected with others inside and outside the workplace and hence it enhances their job performance.

The hypothesis examining the relationship between self status seeking and job performance was rejected which indicates that the performance of employees will not be enhanced by increased self status through Facebook and this finding was contradictory to previous findings such as De Dreu and Nauta (2009) and Judge and Bono (2001). One of the reasons can be people in Pakistani context dont develop their self sta- 
Table 3: Mediated Regression Analysis through A. F. Hayes

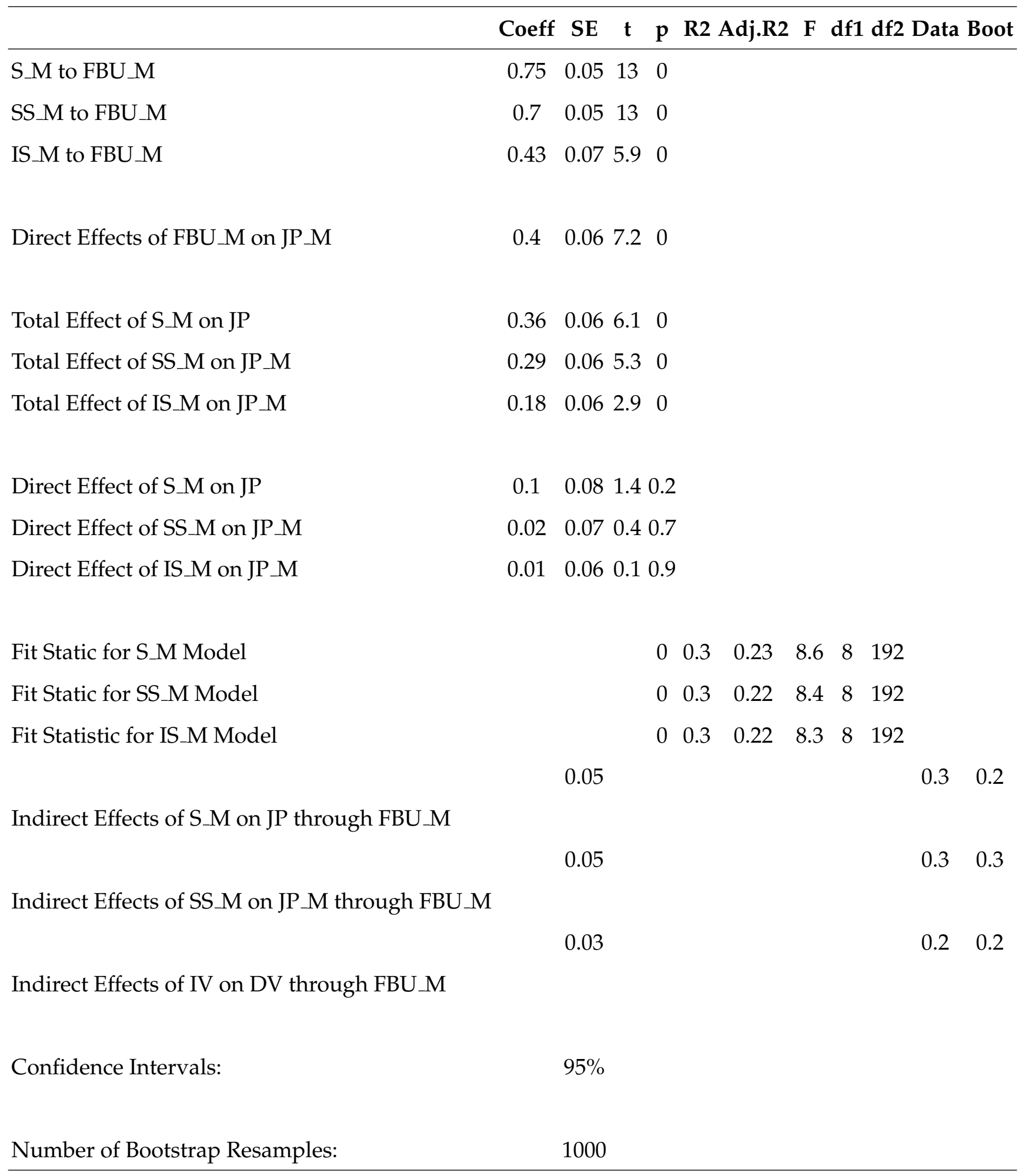

tus to enhance their performance rather they might be trying to develop their self status for other purposes such as to get recognition, to get respect from others and to develop self esteem and self actualization. As Lampel and Bhalla (2007) suggest that developing self status through Facebook or other networks can have two types of motives, internal or external. The internal motives might seek to psychological or emotional goals while external goals like economic, monetary and social advantage. This study suggests that people in Pakistan develop self status through Facebook not for the external (monetary) goals, rather they seek emotional 
and psychological state of well being for developing their status. This can have indirect effects on enhancing job performance of the employees, though the direct effects have not been observed.

Results indicate that Facebook usage mediates the relationship between self status seeking and job performance. This is an interesting finding indicating that if employees use Facebook more i.e. the intensity of using Facebook will be more for fulfilling the need of self status seeking, then it will lead to increased performance. The findings suggest a significant relationship between self status seeking and Facebook usage, which means people try to develop their self status by using Facebook and the more is their urge for developing their status, the more their Facebook Usage will be. As Lampel and Bhalla (2007) suggest that the type of social ties and nature of interaction determine that a person will try to develop which kind of self status, external or internal. The social ties will be strong when Facebook usage intensity will be more and there will be increased interaction among people that may allow them to develop their status for either external or internal goals. Seeking self status for external motives (economic and monetary) may directly lead to enhanced performance of the employees, which gives them economic benefits, hence the findings of this study support previous findings that job performance will be enhanced by developing self status by using Facebook (Borgatti and Foster, 2003; Judge and Hurst, 2008).

The hypothesis examining the relationship between information sharing through Facebook and job performance is found to be rejected in this study, which contradicts previous literature such as Sparrowe et al. (2011) who studied direct relationship of information sharing through networks and job performance of employees. The reason of this result can be that individuals may not be able to access accurate, valid and reliable information on Facebook. Some of them may find information from others that is incorrect or inadequate to act upon. As everyone expresses information according to their own knowledge and experience, the information acquired may not always be valid for every kind of context and situation. For example if some employees have interaction with each other on Facebook, having different experiences and working context, the factors that have led to ones success in a particular context may not be able to contribute to enhance the performance of the other in another context. Another reason may be the communication barrier between the people communicating through Facebook. A simple Facebook message or information provided on a Facebook page may not be enough to convey the whole idea to others. Some information needs to be properly disseminated through verbal and non verbal channels. Another reason seems to be the diversified information on Facebook, in such an environment where there is a lot of information through different sources, one may not be able to identify wrong vs right and effective vs ineffective information that may lead to increased confusion and hence it may not contribute to developing the performance of the employee.

However, findings suggest that Facebook usage mediates the relationship between information sharing and job performance, and are supported by literature (Zhou et al., 2007). Information sharing is significantly related to Facebook usage which means people who seek to share with or acquire information from others may use Facebook intensely. In simple words, employees who need to share information through Facebook will use Facebook more. Using Facebook more will lead them to gather a lot of information and if that information will be used effectively in proper direction, it may lead to enhanced performance. When Facebook usage will be more, employees will be able to judge the right vs wrong and effective vs ineffective information because they will be having access to more sources of information and knowledge. For effective sharing of information, there should be effective usage intensity of Facebook that can help employees to collect different ideas and knowledge out of which they can screen the ideas that are best suited in their working context and in this way it will lead to increased employee performance.

The findings of this study show significant direct effect of Facebook usage on job performance indicating that there is direct effect of Facebook usage on job performance, contradicting some studies of past (Lieberman and Miller, 2011; Lim, 2002; Malachowski, 2005) while supporting some other studies (Alloway et al., 2013; Bakker et al., 2004; Somers and Casal, 2009). The results of the current study suggest that Facebook in the workplace can work as an effective mechanism in boosting the performance of employees. In the model, there is significant total effect of Facebook usage on job performance of employees; hence organizations can use it as a tool for enhancing the job performance by allowing its usage at the workplace.

\subsection{Implications}

This study adds to the emerging body of knowledge which examines the role of Facebook Usage in the workplace on job performance and finds out its determinants that constitute its usage at workplace. The changes in the way people communicate and connect with each other and in the nature of work, as a result of globalization and technological advances have elevated the importance of studying the effect of Facebook usage in the workplace. This study makes a unique contribution to the management information systems and human resource fields, in particular, and to international business, in general, by considering the relationship of Facebook usage in the workplace to job performance of employees from the Call Center industry 
that has very emerging effects in the Telecom Sector of Pakistan.

This study is an attempt to fill the gap in the social networking site literature by collecting data from employees in the workplace. Overall, the study has provided support for several unique relationships and thus makes important contributions to the literature. The results suggest that, in order to obtain better work-related outcomes and job performance, employees should involve themselves in Facebook usage as a main source of social support. Establishing a social network with people from different backgrounds through social networking sites would help employees become happier at work, become more innovative, share more ideas, feeling recognized and perform better. In sum, this study suggests that organizations should add the adoption of the use of Facebook in the workplace to their arsenal of practices that enhance organizational commitment and job performance.

\subsection{Limitations and Future Directions}

No empirical study is without limitations. One of the limitations of this study is its reliance on selfreported measurements. For example, since the use of social networking sites in the workplace is sometimes frowned upon and reporting not using it intensely at work would be viewed as a desirable behavior of employees, individuals self-assessment of their social networking site in the workplace may be subject to social desirability bias, presenting ones self in a favorable image. The composition of the sample is another limitation of this study. In particular, the sample collected data from only one particular industry i.e. telecom sector and it included a small number of observations from women as most of the respondents in our sample were men thus limiting the ability to generalize the findings. Another limitation of this study comes from the fact that the data collected were from only two cities of Pakistan. Therefore, caution is advised in making generalizations from the findings of this study. This study is a cross-sectional research design which makes it difficult to determine causality. This discussion, therefore, concludes that future studies greatly need to establish the causality with longitudinal designs. Furthermore, it focused on three main determinants of Facebook usage in organizations, there could be other determinants as well.

The results of this study have several implications for academics and practitioners. Future studies can explore what Facebook usage in the workplace will bring on other job outcomes such as reduced stress and burnout etc. Future studies can study other determinants of Facebook usage at workplace. Further studies can also evaluate the comparison between the positive and negative impacts of Facebook Usage at the workplace. Furthermore it can be investigated which variable moderates these relationships. This study collected cross- sectional data at a single point in time through a one-time issuance of the survey instrument. To more holistically explore the relationship between online social networking site and its association with work-related outcomes including job performance, a longitudinal study design is worth investigating. This longitudinal study would allow researchers to better track the growth of participants use of social networking sites which in turn could offer greater insight into the association between social networking use and job performance.

\section{References}

Alhabash, S., Chiang, Y.-h., and Huang, K. (2014). Mam \& $\mathrm{u} \& \mathrm{~g}$ in taiwan: Differences in the uses and gratifications of facebook as a function of motivational reactivity. Computers in Human Behavior, 35:423-430.

Alloway, T. P., Horton, J., Alloway, R. G., and Dawson, C. (2013). Social networking sites and cognitive abilities: Do they make you smarter? Computers $\mathcal{E}$ Education, 63:10-16.

Bakker, A. B., Demerouti, E., and Verbeke, W. (2004). Using the job demands-resources model to predict burnout and performance. Human resource management, 43(1):83-104.

Belk, R. (2010). Sharing. Journal of consumer research, 36(5):715734.

Borgatti, S. P. and Foster, P. C. (2003). The network paradigm in organizational research: A review and typology. Journal of management, 29(6):991-1013.

Boyd, D. (2007). m., \& ellison, nb (2007). Social network sites: Definition, history, and scholarship. Journal of ComputerMediated Communication, 13(1):11.

Carson, J. B., Tesluk, P. E., and Marrone, J. A. (2007). Shared leadership in teams: An investigation of antecedent conditions and performance. Academy of management Journal, 50(5):1217-1234.

Chung, S., Lee, K. Y., and Choi, J. (2014). Exploring digital creativity in the workspace: The role of enterprise mobile applications on perceived job performance and creativity. Computers in Human Behavior, 42:93-109.

Correa, T., Hinsley, A. W., and De Zuniga, H. G. (2010). Who interacts on the web?: The intersection of users personality and social media use. Computers in Human Behavior, 26(2):247-253.

Cross, R. and Cummings, J. N. (2004). Tie and network correlates of individual performance in knowledge-intensive work. Academy of management journal, 47(6):928-937.

De Dreu, C. K. and Nauta, A. (2009). Self-interest and otherorientation in organizational behavior: implications for job performance, prosocial behavior, and personal initiative. Journal of Applied Psychology, 94(4):913. 
Ellison, N. B., Steinfield, C., and Lampe, C. (2007). The benefits of facebook friends: social capital and college students use of online social network sites. Journal of ComputerMediated Communication, 12(4):1143-1168.

Ferreira, A. and Du Plessis, T. (2009). Effect of online social networking on employee productivity. South African Journal of Information Management, 11(1):1-11.

Fogel, J. and Nehmad, E. (2009). Internet social network communities: Risk taking, trust, and privacy concerns. Computers in human behavior, 25(1):153-160.

Hargittai, E. (2008). Digital na (t) ives? variation in internet skills and uses among members of the net generation. Sociological inquiry, 80(1):92-113.

Hugl, U. (2011). Reviewing person's value of privacy of online social networking. Internet Research, 21(4):384-407.

Jenny, W., Lin, C.-F. C., Wei-Chieh, W. Y., and Emily, W. (2013). Meaningful engagement in facebook learning environments: Merging social and academic lives. Turkish Online Journal of Distance Education, 14(1).

Johnson, M. K., Rowatt, W. C., and Petrini, L. (2011). A new trait on the market: Honesty-humility as a unique predictor of job performance ratings. Personality and Individual Differences, 50(6):857-862.

Judge, T. A. and Bono, J. E. (2001). Relationship of core selfevaluations traitsself-esteem, generalized self-efficacy, locus of control, and emotional stabilitywith job satisfaction and job performance: A meta-analysis. Journal of applied Psychology, 86(1):80.

Judge, T. A. and Hurst, C. (2008). How the rich (and happy) get richer (and happier): relationship of core selfevaluations to trajectories in attaining work success. Journal of Applied Psychology, 93(4):849.

Kotlarsky, J. and Oshri, I. (2005). Social ties, knowledge sharing and successful collaboration in globally distributed system development projects. European Journal of Information Systems, 14(1):37-48.

Lampel, J. and Bhalla, A. (2007). The role of status seeking in online communities: Giving the gift of experience. Journal of Computer-Mediated Communication, 12(2):434-455.

Lawler, E. E. and Porter, L. W. (1967). Antecedent attitudes of effective managerial performance. Organizational behavior and human performance, 2(2):122-142.

Liberman, B., Seidman, G., Mckenna, K. Y., and Buffardi, L. E. (2011). Employee job attitudes and organizational characteristics as predictors of cyberloafing. Computers in Human behavior, 27(6):2192-2199.

Lieberman, A. and Miller, L. (2011). Teacher leadership, volume 17. John Wiley \& Sons.

Lim, V. K. (2002). The it way of loafing on the job: cyberloafing, neutralizing and organizational justice. Journal of Organizational Behavior, 23(5):675-694.
Lin, K.-Y. and Lu, H.-P. (2011). Why people use social networking sites: An empirical study integrating network externalities and motivation theory. Computers in Human Behavior, 27(3):1152-1161.

Malachowski, D. (2005). Wasted time at work costing companies billions. San Francisco Chronicle, 11.

Mathieu, J., Maynard, M. T., Rapp, T., and Gilson, L. (2008). Team effectiveness 1997-2007: A review of recent advancements and a glimpse into the future. Journal of management, 34(3):410-476.

Oh, H., Chung, M.-H., and Labianca, G. (2004). Group social capital and group effectiveness: The role of informal socializing ties. Academy of management journal, 47(6):860875.

Pihlström17, M. and Brush18, G. J. (2008). Comparing the perceived value of information and entertainment mobile services. Perceived Value of Mobile Service Use and Its Consequences, page 204.

Porter, L. W. and Lawler, E. E. (1968). Managerial attitudes and performance.

Reinholt, M., Pedersen, T., and Foss, N. J. (2011). Why a central network position isn't enough: The role of motivation and ability for knowledge sharing in employee networks. Academy of Management Journal, 54(6):1277-1297.

Ribeiro Soriano, D., Assis-Dorr, H., Palacios-Marques, D., and Merigó, J. M. (2012). Social networking as an enabler of change in entrepreneurial brazilian firms. Journal of Organizational Change Management, 25(5):699-708.

Rosenberg, J. and Egbert, N. (2011). Online impression management: Personality traits and concerns for secondary goals as predictors of self-presentation tactics on facebook. Journal of Computer-Mediated Communication, 17(1):1-18.

Scott, G. G. (2014). More than friends: Popularity on facebook and its role in impression formation. Journal of ComputerMediated Communication, 19(3):358-372.

Siu, O.-1., Lu, C.-q., and Spector, P. E. (2013). Direct and indirect relationship between social stressors and job performance in greater china: The role of strain and social support. European Journal of Work and Organizational Psychology, 22(5):520-531.

Somers, M. J. and Casal, J. C. (2009). Using artificial neural networks to model nonlinearity: The case of the job satisfactionjob performance relationship. Organizational Research Methods, 12(3):403-417.

Sparrowe, R. T., Liden, R. C., Wayne, S. J., and Kraimer, M. L. (2011). Social networks and the performance of individuals and groups. Academy of management journal, 44(2):316325.

Steinfield, C., Ellison, N. B., and Lampe, C. (2008). Social capital, self-esteem, and use of online social network sites: A longitudinal analysis. Journal of Applied Developmental Psychology, 29(6):434-445. 
Sumanth, J. J. and Cable, D. M. (2011). Status and organizational entry: How organizational and individual status affect justice perceptions of hiring systems. Personnel Psychology, 64(4):963-1000.

Tseng, S.-M. and Huang, J.-S. (2011). The correlation between wikipedia and knowledge sharing on job performance. Expert systems with applications, 38(5):6118-6124.

Turban, E., Bolloju, N., and Liang, T.-P. (2011). Enterprise social networking: Opportunities, adoption, and risk mitigation. Journal of Organizational Computing and Electronic Commerce, 21(3):202-220.

Ugrin, J. C., Odom, M. D., Pearson, J. M., and Bahmanziari, T. R. (2012). Exploring the effects of social exchange relationships on the scholarly productivity of new faculty members in accounting. American Journal of Business Education (Online), 5(4):385.

Valle, M. A., Varas, S., and Ruz, G. A. (2012). Job performance prediction in a call center using a naive bayes classifier. $E x$ pert Systems with Applications, 39(11):9939-9945.
Wilcox, K. and Stephen, A. T. (2013). Are close friends the enemy? online social networks, self-esteem, and self-control. Journal of Consumer research, 40(1):90-103.

Wills, D. and Reeves, S. (2009). Facebook as a political weapon: Information in social networks. British Politics, $4(2): 265-281$.

Wu, L. (2013). Social network effects on productivity and job security: Evidence from the adoption of a social networking tool. Information systems research, 24(1):30-51.

Zhou, L., Wu, W.-p., and Luo, X. (2007). Internationalization and the performance of born-global smes: the mediating role of social networks. Journal of international business studies, 38(4):673-690.

Zou, X. and Ingram, P. (2013). Bonds and boundaries: Network structure, organizational boundaries, and job performance. Organizational behavior and human decision processes, 120(1):98-109. 